Mongolian Academy of Sciences
Mongolian Journal of Chemistry
Institute of Chemistry \& Chemical Technology

\title{
Persistent organic pollutants (PCBs and OCP) in air and soil from Ulaanbaatar and the Lake Hovsgol region, Mongolia
}

\author{
Mamontova E.A. ${ }^{1}$, Tarasova E.N. ${ }^{1}$, Ganchimeg D. ${ }^{2}$, Kuzmin M.I. ${ }^{1}$, Mamontov A.A. ${ }^{1}$, \\ Khomutova M.Yu. ${ }^{1}$, Burmaa G. ${ }^{2}$, Odontuya G. ${ }^{2}$, Erdenebayasgalan G. ${ }^{3}$ \\ ${ }^{1}$ A.P. Vinogradov Institute of Geochemistry, Siberian Branch, Russian Academy of Sciences \\ ${ }^{2}$ Institute of Chemistry and Chemical Technology, Mongolian Academy of Sciences \\ 3 Ministry of nature, environment and tourism, Mongolia
}

\begin{abstract}
The investigations of POPs in soil and air in three urban and rural sites of the Mongolia are presented. The POPs distribution in air repeats the POPs distribution in soil on the area investigated. The POPs levels in soil and air are lower than maximum permissible concentrations (MPC) and preliminary permissible concentrations (PPC) of PCBs and OCP accepted in Russia. POPs levels in Mongolian soil obtained in the investigation are comparable with those from background areas of the world. POPs levels in Mongolian air are in the frame of concentrations found in the world. The PCB homological pattern in soil near electric power station in Ulaanbaatar is close to homological pattern in PCB technical mixture (Sovol or Arochlor 1254). The homological patterns in soil from other sites changed due to the redistribution of PCB congeners in the environment. The ratio of DDT and its metabolites indicates fresh entrance of DDT in the environment of Mongolia due to the atmospheric transboundary transport from countries using DDT (China, India) or from local agricultural sources. Hazard indexes in result from human exposure with POPs in soil and air are lower by 2-4 orders than 1 that denotes the possible default of disturbances in target organ and system. CR under the same scenario corresponds to the first diapason that is taken by population as negligible risk, not differ from usual everyday risks. Such risks don't require additional measures for the reducing of risks and their levels are a subject of periodical control. The necessity of additional investigation of POPs distribution and the fate in Mongolian environment is indicated.
\end{abstract}

\section{Introduction}

Dersistent organic pollutants (POPs) is the group of dangerous compounds with common properties. They are persistent in environment; bioaccumulative along food chain; toxic for human and other alive organisms (AMAP, 1998; Sunden, 1998). POPs bring remote effects including cancer, disturbance of development, dysfunction of reproductive, endocrine and immune systems and other health problems. POPs are able to long range transport. POPs can be found in remote areas, far from primary sources of formation and application (AMAP, 1998). The measures protecting human health and the environment form negative effects of the compounds are taken on the national, regional and international levels. The measures provide elimination and/or reduce the emission, release of POPs into environment and, if it is necessary, the cessation of production and application. Stockholm Convention on the persistent organic pollutants was adopted on the Conference of the Parties and opened for the signing 22 May 2001. More then 150 
countries have signed the convention. The Convention entered into force on 17 May 2004 (http://www.chm.pops.int).

The list of compounds in the Stockholm Convention consists originally of 12 individual substances and group of compounds. The list A (the ban of production and application) of Stockholm Convention in version of 2001 consists of aldrin, chlordane, dieldrin, endrin, heptachlor, hexachlorobenzene (HCB), mirex, toxaphen, polychlorinated biphenyls (PCBs). DDT is included in the list $\mathrm{B}$ (the limitation of production and application). Polychlorinated dibenzo-para-dioxins (PCDDs) and dibenzofurances (PCDFs), PCBs and HCB are included in the list $\mathrm{C}$ (the reduction and liquidation of emissions in result from unpremeditated production). The possibility and the procedure of addition of new compounds are provided by the Stockholm Convention. Nine additional compounds including $\alpha$-hexachlorocyclohexane $\quad(\alpha$ $\mathrm{HCH}), \beta-\mathrm{HCH}$ and lindan $(\gamma-\mathrm{HCH})$ were included in the list of the Stockholm Convention in 2009 by the Conference of the Parties of the Convention. The amendments entered into force on 26 August 2010 (http://www.chm.pops.int).

Mongolia signed the Stockholm Convention during the Conference of Plenipotentiaries in 2002, 17 May. State Great Khural of Mongolia ratified the Stockholm Convention 2004, 30 April (http://www.chm.pops.int). National plan on POPs was heard and approved at the session of Government of Mongolia in 2006, May 3 (National Implementation Plan, 2006).

$\mathrm{HCB}, \mathrm{PCBs}$ and organochlorine pesticides included in the list of Stockholm convention have never been produced in Mongolia (National implementation plan, 2006). Pesticides were purchased in other countries including former USSR. Aldrin, chlordane, dieldrin, heptachlor, HCB and $\mathrm{HCH}$ were used since 1950s to control internal parasite of livestock, treatment of fences and grasslands against grasshoppers. DDT, endrin, mirex and toxaphene have never been used on the territory of Mongolia (National implementation plan, 2006). Ministerial Decree № 75 from 14 May 1997 banned the usage of aldrin, dieldrin, chlordane, DDT, endrin, $\mathrm{HCB}$, heptachlor and toxaphen in Mongolia.

PCBs have been used previously and they being used at present days in industrial transformers. The inventory of 2004-2005 found that there are 4637 transformers of 35 types in Mongolia at that time (National implementation plan, 2006). 96 percents of the transformers were produced in Russia in 1968-1980s. The rest transformers were produced in China $(2.1 \%)$, Japan $(0.7 \%)$, Germany (0.7 \%), Bulgaria, Romania, Korea, Czechoslovakia and Hungary $(0.5 \%)$. The investigation of 557 samples of transformer oil indicates that 12.4 percents of the samples don't contents PCBs, 7.7 percents of the samples content PCBs more than $50 \mathrm{ppm}$. 81.3 percents of transformers are used or kept in the central district of Ulaanbaatar and other large cities. Inadequate conditions of application, storage and utilization of obsolete transformers and pesticides can result in pollution of the environment and increasing of health risk for population due to the exposure with PCBs and OCPs. For example, the Erdenet Mining Corporation used 2 tones of waste of transformer oil on the roads in order to reduce road slippery in winter time. The analyses of soil samples found the PCBs concentrations more than $50 \mathrm{ppm}$ (National implementation plan, 2006). The investigation of POPs in air in the area of settlement of Khankh and sediments and zoolplankton from Lake Hovsgol indicate that the compounds arrive to the region as a result of atmospheric transport (Goreglyad et al., 2007; Mamontova et al., 2009a). However the impact of small local sources was found also (Mamontova et al., 2009a).

The aim of the paper is to present the first data on PCB and organochlorine pesticides levels in air and soil samples from Ulaanbaatar, its residential suburbia Yargayat-bogino and in Tarialan somon Hovsgol aimag.

\section{Experimental \\ Samples collection}

Passive air samplers (PAS) have been obtained by using of polyurethane foam disks (PUF-disks) and used to investigate POPs 
levels in air. The construction of PAS used in the study was similar to those described in Pozo et al. (2009). The theory of the passive sampling using similar devices was described by Shoeib and Harner (2002). PUF-disks were precleaned by Soxhlet extraction for 10 $\mathrm{h}$ using dichloromethane (DCM). PAS were installed in the zone of influence of electric power station III in Ulaanbaatar, in Yargaytbogino in $18 \mathrm{~km}$ to the north-east from Ulaanbaatar and in rural area in the southwest from Lake Hovsgol (Tarialan somon Hovsgol aimag). The position data and time of the installation of PAS are presented in Table 1 and Fig. 1.

In addition soil was sampled in the PAS installation sites in summer of 2009. Soil samples were collected using tube metal sampler with diameter of $5 \mathrm{~cm}$ from five sites by the method of envelope. Soil samples were dried under a room temperature up to air-dry condition. The fraction of $2 \mathrm{~mm}$ was taken for the analysis.

Soil samples and PUF-disks were stored at $30^{\circ} \mathrm{C}$ prior to the analysis in laboratory of the Institute of Geochemistry, Siberian Branch of RAS in Irkutsk, Russia

Table 1. The description of air sampling

\begin{tabular}{|c|c|c|c|c|}
\hline & 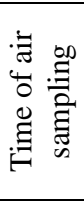 & 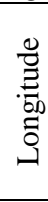 & 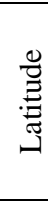 & 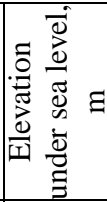 \\
\hline 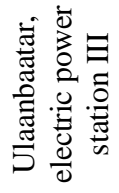 & 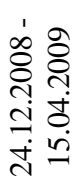 & $\begin{array}{l}\infty \\
\infty \\
\infty \\
n \\
\infty \\
\gamma\end{array}$ & $\begin{array}{l}\hat{\infty} \\
\text { N } \\
\text { ñ } \\
\text { o̊ } \\
\text { o }\end{array}$ & $\stackrel{\infty}{\stackrel{\infty}{\beth}}$ \\
\hline 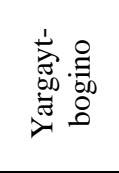 & 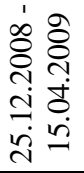 & 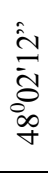 & 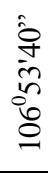 & $\begin{array}{l}\text { ¿ } \\
\cong\end{array}$ \\
\hline 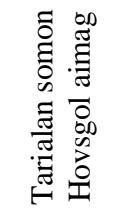 & 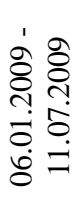 & 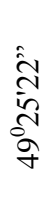 & $\begin{array}{l}\hat{\tilde{N}} \\
\text { in } \\
\text { in } \\
\tilde{0}\end{array}$ & $\stackrel{t}{2}$ \\
\hline
\end{tabular}

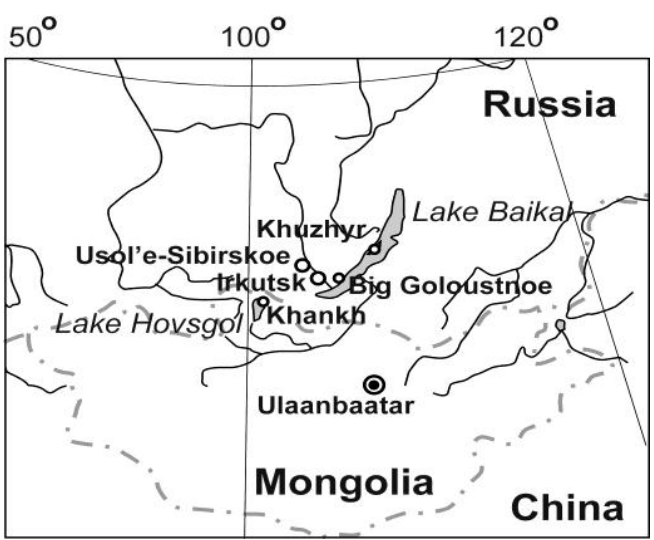

Fig. 1. The scheme of the region investigated.

\section{Sample extraction and analysis}

Samples were analyzed for 28 PCBs, including indicator PCBs (28, 52, 101/90, $138,153,180), p, p$ '-DDT, $p, p^{\prime}-\mathrm{DDD}, p, p^{\prime}-$ DDE, $\alpha-\mathrm{HCH}, \gamma-\mathrm{HCH}$, trans-chlordane (TC), cis-chlordane (CC), trans-nonachlore (TNCL) and cis-nonachlore (CNCL) at the laboratories of the Institute of Geochemistry in Irkutsk (Russia).

PUF disks were Soxhlet extracted using DCM. Surrogate standards (PCB 14 and PCB 65) were added in solvent prior to the extraction. The extract was purified on an aluminum oxide / silica gel / silica gel $+\mathrm{H}_{2} \mathrm{SO}_{4}$ column.

Soil were Soxhlet extracted using acetone/hexane (1:1). Surrogate standards (PCB 14 and PCB 65) were added in solvent prior to the extraction. Large molecules in the extract were separated by gel permiation chromatography (GPC) on Bio-Beads S-X3. This was followed by a column consisting of $3 \mathrm{~g} \mathrm{Al}_{2} \mathrm{O}_{3}$ (activated at the $900^{\circ} \mathrm{C}$ ), $3 \mathrm{~g}$ silica gel (activated at the $450^{\circ} \mathrm{C}$ ) and $3 \mathrm{~g} \mathrm{Na}_{2} \mathrm{SO}_{4}$. Published analytical methods were used (Mamontov et al., 2004; Mamontova et al., 2009).

The POPs were analyzed using gas chromatography with a ${ }^{63} \mathrm{Ni}$ electron-capture detector (GC-ECD). The Hewlett - Packard 5890 series II GC was equipped with a 0.25 $\mu \mathrm{m} \times 60 \mathrm{~m}$ DB-5 capillary column (J\&W Scientific). The amounts of PCBs and OCPs in air in sampling time were obtained assuming that sampling rates were $3.5 \mathrm{~m}^{3}$ in a day. 


\section{Human health risk assessment}

The carcinogenic and noncarcinogenic human health risks were calculated under the "Guidance on risk assessment..." (R 2.3.10.1920-04). The data on the inhalation rate for adult $\left(20 \mathrm{~m}^{3}\right.$ per a day), the index of accidental ingestion of soil particles by adult human $(50 \mathrm{mg} / \mathrm{kg}$ per a day), adult body mass $(70 \mathrm{~kg})$, the rate of exposure per year $(365$ days) and the lifelong scenario of exposure (70 years) ( $\mathrm{R}$ 2.3.10.1920-04) were used for calculations.

\section{Results and Discussion}

Results are presented in Tables 2-3 and Figures 2-3.

Soil. The levels of POPs in soil from Mongolia were equal to 3.97 - $13.2 \mathrm{ng} 28$ PCB congeners/g dry weight including $1.43-$ $5.94 \mathrm{ng} 6$ indicator $\mathrm{PCBs} / \mathrm{g}, 0.06-4.28 \mathrm{ng}$ total DDTs/g, $0.02-0.81 \mathrm{ng} \alpha+\gamma-\mathrm{HCHs} / \mathrm{g}$, and $0.0045-0.03 \mathrm{ng} \mathrm{HCB} / \mathrm{g}$. These concentrations are lower than maximum permissible concentrations (MPC) and preliminary permissible concentrations (PPC) of PCBs and OCP accepted in Russia (The control chemical and biological parameters of the environment, 1998 and GN 1.2.1323-03).

PCB levels obtained in Mongolian soil are comparable with levels in soil from background regions of the world (5.41 (0.026 - 96.9) ng/g) (Meijer et al., 2003), rural, background and suburb areas of the Lake Baikal region $(0.45-32 \mathrm{ng} / \mathrm{g}$ ) (Mamontov et al., 2004) and lower than those in industrial areas. For example PCB levels in soil from the town of Usol'e-Sibirskoe in the Lake Baikal Region comes to $530 \mathrm{ng} / \mathrm{g}$ (Mamontov et al., 2004).

The HCB levels in soil from Mongolia are comparable or lower than in soil from background regions of the world $(0.68(0.01-$ $5.21) \mathrm{ng} / \mathrm{g}$ ) (Meijer et al., 2003) and soil of the Lake Baikal region $(0.02-72 \mathrm{ng} / \mathrm{g})$ (Mamontov et al., 2004). DDTs and $\mathrm{HCH}$ concentrations in soil are comparable or lower than in Lake Baikal Region (Mamontov et al., 2004), in forest soil of background areas of Austria (nd-22 ng/g and $0.6-6.6 \mathrm{ng} / \mathrm{g}$, accordingly) (Weiss et al., 2000), in mountain areas of Europe $(1.7-13$ and $0.08-0.49$ ng/g, accordingly) (Grimalt et al., 2004), and considerably lower than in rural soil from China (Guangzhou) (3.58 - 830 and $0.19-42$ ng/g, accordingly) (Chen et al., 2005).

The highest accumulation levels (concentrations expressed on the square) of PCB and OCP were found in soil from the zone of the atmospheric influence of electric power station III in Ulaanbaatar (Table 2). In Yargayt-bogino, residential suburbia of Ulaanbaatar, the PCBs, DDTs and $\mathrm{HCHs}$ levels are 2-14 times lower and amount to 22, 3.12 and $0.25 \mathrm{ng} / \mathrm{cm}^{2}$, correspondingly. The HCB levels in soil from Yargayt-bogino were insignificantly higher than in Ulaanbaatar. The lowest accumulation levels were found in soil from rural area in the south-west from Lake Hovsgol (Tarialan somon Hovsgol aimag).

The ratio of individual compounds in sum of POPs group is also different. For example the homological composition of PCB in soil sampled nearby the electric power station in Ulaanbaatar is different from the PCB composition in soil from Yargaytbogino and Tarialan somon Hovsgol aimag (Fig. 2). The homological composition of PCB in soil nearby electric power station is similar to those in soil from Usol'e-Sibirskoe (the Lake Baikal Region, Russia) and in technical mixture of PCB (Sovol or Arochlor 1254) (Fig. 2). Whereas the homological compositions of PCB in the rest Mongolian soil samples changed due to the redistribution of PCB congeners in the environment because of different physical-chemical properties of the individual PCB congeners (Wania, Mackay, 1996). 

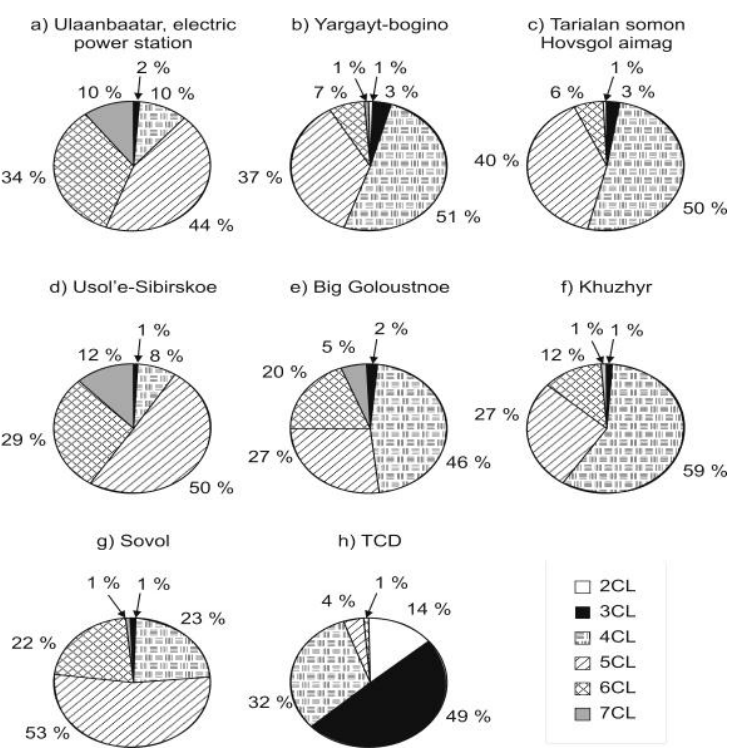

Fig. 2. The PCB homological pattern in soil from Mongolia (Ulaanbaatar (a), Yargayt-bogino (b) and Tarialan somon Hovsgol aimag (c) (present investigation), the Lake Baikal region

(the settlements of Usol'e-Sibirskoe (d), Big

Goloustnoe (e), Khuzhyr (f)) (Mamontova et al.,2009) and PCB technical mixtures produced in former USSR (Sovol (g) and TCD (h))

(Ivanov, Sendell, 1991) (\%).

The cluster analysis of PCB congener patterns in soil samples from Mongolia and some soil samples from the Lake Baikal region allow to distinguish two groups (Fig. 3). The first group consists of soil samples from Yargaytbogini and Tarialan somon Hovsgol aimag (Mongolia) and settlements Khuzhyr and Big Goloustnoe located on Lake Baikal in the zone of atmospheric impact from industrial centers of the Irkutsk Region. The second group unites the soil samples from the cities of Ulaanbaatar and Usol'e-Sibirskoe and technical mixture of PCB (Sovol or Arochlor 1254). It should be noted that the PCB congener pattern in both groups differ from the PCB congener patterns in TCD (trichlordiphenil) being another technical mixture produced in former USSR (Ivanov, Sendell, 1991).

Table 2. The POPs accumulation levels in soil and concentrations in air from Mongolia

\begin{tabular}{|c|c|c|c|c|c|c|}
\hline \multirow{2}{*}{} & \multicolumn{2}{|c|}{ Ulaanbaatar } & \multicolumn{2}{c|}{ Yargayt-bogino } & \multicolumn{2}{c|}{$\begin{array}{c}\text { Tarialan somon } \\
\text { Hovsgol aimag }\end{array}$} \\
\cline { 2 - 7 } & soil & air & Soil & air & soil & air \\
\cline { 2 - 7 } & $\mathrm{ng} / \mathrm{sm}^{2}$ & $\mathrm{pg} / \mathrm{m}^{3}$ & $\mathrm{ng} / \mathrm{sm}^{2}$ & $\mathrm{pg} / \mathrm{m}^{3}$ & $\mathrm{ng} / \mathrm{sm}^{2}$ & $\mathrm{pg} / \mathrm{m}^{3}$ \\
\hline HCB & 0.14 & 20 & 0.21 & 20 & 0.009 & 7,6 \\
\hline $\begin{array}{c}\text { Total } \\
\text { HCHs }\end{array}$ & 3.56 & $78^{*}$ & 0.25 & $21.5^{*}$ & 0.04 & $15.5^{*}$ \\
\hline $\begin{array}{c}\text { Total } \\
\text { DDTs }\end{array}$ & 18.8 & 335 & 4.12 & 185 & 0.11 & 237 \\
\hline
\end{tabular}

\begin{tabular}{|c|c|c|c|c|c|c|}
\hline $\begin{array}{c}\text { Total } \\
\text { PCBs }\end{array}$ & 58 & 2640 & 21.6 & 1650 & 7.7 & 1730 \\
\hline $\begin{array}{c}\text { Total } \\
\text { indica } \\
\text { tor } \\
\text { PCBs }\end{array}$ & 26 & 965 & 8.4 & 610 & 2.7 & 625 \\
\hline
\end{tabular}

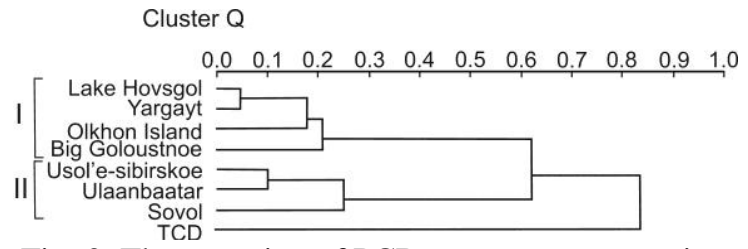

Fig. 3. The grouping of PCB congener patterns in soil from Mongolia and the Lake Baikal region with the cluster method.

Thus, the homological and congener pattern of PCB in soil nearby electric power station assumed the presence of source. It is possible that the transformers containing PCB technical mixture (Sovol or Arochlor 1254) can be the source in this case. These transformers can be functioned or/and stored on the electric power station.

The ratio of $\alpha$ - and $\gamma$-isomers of $\mathrm{HCH}$ are different in samples investigated. The ratio $\alpha / \gamma-\mathrm{HCHs}$ are equal to 6.7 in Ulaanbaatar, 2.5 in Yargayt-bogino and 1.05 in Tarialan somon Hovsgol aimag. These values of $\alpha / \gamma-\mathrm{HCHs}$ are evidence of the preferred application of technical mixture of $\mathrm{HCH}$ in the Ulaanbaatar region and additional using of lindan in the rural areas of Hovsgol aimag. The technical mixture of $\mathrm{HCH}$ consists of $53-70$ percents of $\alpha-\mathrm{HCH}$ and 11 -18 percents of $\gamma-\mathrm{HCH}$. While $\gamma-\mathrm{HCH}$ is the main component of lindan (90 percents) (Mel'nikov, 1987).

The ratio of DDT/DDE above 1 indicates the recent using of the pesticide. The ratios of DDT and DDE were higher 1 in all soil samples from Mongolia (13 in Ulaanbaatar and $1.36-1.85$ in Yargaytbogino and Hovsgol aimag).

Atmospheric air. The data on the levels of POPs in air of Mongolia are presented in Table 2. The distribution of POPs in air repeats the distribution of POPs in soil on the area investigated. Data obtained in Mongolian air were lower than MPC and PPC of PCBs and OCP accepted in Russia (1 $\mu \mathrm{g} / \mathrm{m}^{3}$ for $\mathrm{PCB}, 0.001 \mathrm{mg} / \mathrm{m}^{3}$ for $\mathrm{HCH}$ and DDTs and $0.013 \mathrm{mg} / \mathrm{m}^{3}$ for HCB) (The 
control chemical and biological parameters of the environment, 1998 and GN 1.2.1323-03).

The values of total PCB in three areas of Mongolia in the period from January-April till July 2009 were higher than the data obtained for the settlement of Khankh located on the northern coast (May-June 2008 (96 pg $\left.28 \mathrm{PCBs} / \mathrm{m}^{3}\right)$ ) (Mamontova et al., 2009a). The phenomena can be result from different season of air sampling. The mean temperature in January in the Lake Hovsgol Region and the city of Ulaanbaatar come to 24 and about 20-22 ${ }^{\circ} \mathrm{C}$ below zero, accordingly (absolute minimum are 45.3 and $49{ }^{\circ} \mathrm{C}$ below zero) (Atlas of Mongolia, 2004). In addition to the Siberian anticyclone places in the region in winter time and can be the reason of difficulties of the emission scattering from industrial and domestic sources in the season. It is possible that long time of air sampling is one more reason of elevated levels obtained. It is probably that the long time of passive air sampling can give rise to nonlinear accumulation of PCBs investigated in PUFdisks and give a mistake in data obtained (Shoeib, Harner, 2002). The additional investigations are needed to specify levels and the distribution of PCBs in atmospheric air in Mongolia. However, PCBs levels obtained in air of Mongolia are in the frame of data found in the result of GAPS study (Global Atmospheric Passive Sampling) (0.1 - 2830 pg 48 PCBs $/ \mathrm{m}^{3}$ ) in December 2004 (Pozo et al., 2006), in the settlements of the Irkutsk Region $\left(280-2730\right.$ pg $\left.28 \mathrm{PCBs} / \mathrm{m}^{3}\right)$ in JuneAugust 2008 (Mamontova et al., 2009b). But the data obtained for Mongolia are comparable and higher than values found in air of China in September-November 2004 $\left(21\right.$ - 336 pg 29 PCBs/ $\mathrm{m}^{3}$ ) (Jaward et al., 2005), India in July-September 2006 (120 1080 pg $28 \mathrm{PCBs} / \mathrm{m}^{3}$ ) (Zhang et al., 2008) and European countries $(20-1700$ pg 29 PCBs $/ \mathrm{m}^{3}$ ) (Jaward et al., 2004).

The DDT and its metabolites levels in air of the area investigated are also higher than those found in the settlement of Khankh located on the northern coast of the Lake Hovsgol (18.4 pg/m $/ \mathrm{m}^{3}$ ) (Mamontova et al., 2009) and are in the range of values found in the Irkutsk Region (Russia) (65 - 1440 $\mathrm{pg} / \mathrm{m}^{3}$ ) (Mamontova et al., 2009b). They are comparable and lower than levels in air in India $\left(16-2952 \mathrm{pg} / \mathrm{m}^{3}\right)$, where the pesticide is used at presence (Zhang et al., 2008). The DDE levels in air in Mongolia higher and DDT levels are comparable with the levels in air in European countries $(<0.4-25$ and 0.6 $-190 \mathrm{pg} / \mathrm{m}^{3}$ ) (Jaward et al., 2004).

The ratio of DDT/DDE in both air and soil samples from Mongolia are higher 1 (1.43 in Tarialan somon Hovsgol aimag, 1.15 - in Yargayt-bogino and 1.3 - in the zone of atmospheric influence of electrice power station in Ulaanbaatar) and indicate relatively recent entrance of DDT in the environment. In spite of the default of data of the DDT application in Mongolia, the recent entrance of the pesticide in the Mongolian environment is possible as a result of atmospheric transboundary transport from the territory of China or India where DDT is used at presence (Chen et al., 2005; Zhang et al., 2008). It is possible that the local entrance of DDT can result from an application of housekeeping.

$\alpha-\mathrm{HCH}$ levels in air in Tarialan somon Hovsgol aimag and Yargayt-bogino are 2.2. and 1.5 times lower than in air in the settlement of Khankh in the northern coast of Lake Hovsgol (34 pg/m $\mathrm{m}^{3}$ ) (Mamontova et al., 2009a). $\alpha-\mathrm{HCH}$ level in air in Ulaanbaatar is higher than one in Khankh. They are comparable or lower than levels obtained in GAPS-study $\left(0.1-1700 \mathrm{pg} / \mathrm{m}^{3}\right)$ (Pozo et al., 2009), European countries $\left(<14-100 \mathrm{pg} / \mathrm{m}^{3}\right)$ (Jaward et al., 2004), the Irkutsk Region, Russia $\left(19-365 \mathrm{pg} / \mathrm{m}^{3}\right)$ (Mamontova et al., $2009 \mathrm{~b}$ ), India $\left(12-1691 \mathrm{pg} / \mathrm{m}^{3}\right)$ (Zhang et al., 2008).

HCB levels in air in Tarialan somon Hovsgol aimag is lower in 1.9 times, and those in Ulaanbaatar and its suburb are slightly higher than HCB air levels in the settlement of Khankh (14 pg/m $\left.\mathrm{m}^{3}\right)$ (Mamontova et al., 2009a). HCB air contents in Mongolia are comparable or lower than HCB levels in European countries (11 - 50 $\mathrm{pg} / \mathrm{m}^{3}$ ) (Jaward et al., 2004), China (10.4 $\left.461 \mathrm{pg} / \mathrm{m}^{3}\right)$, Singapore $\left(9.5-24.5 \mathrm{pg} / \mathrm{m}^{3}\right)$, Japan $\left(14-95 \mathrm{pg} / \mathrm{m}^{3}\right)$, South Korea $(26-136$ $\mathrm{pg} / \mathrm{m}^{3}$ ) (Jaward et al., 2005).

Human health risk assessment. Data obtained were used for the carcinogenic and no carcinogenic human risk assessment as a 
result of the exposure with complex of POPs investigated (PCBs, DDT and its metabolites, $\alpha$ - and $\gamma$-isomers $\mathrm{HCH}$ and $\mathrm{HCB}$ ) under inhalation of atmospheric air and accidental ingestion of soil particles. The concentrations found in air and soil in the three site of sampling are typical of the areas investigated (the central areas of Hovsgol aimag, Ulaanbaatar and its suburb was assumed.

Hazard Indexes (HI), the indexes of noncarcinogenic risk, were calculated for the following target organs and systems: liver, the central nervous system, immune and endocrine systems, development. HI was $2-$ 4 orders lower than 1 in all cases (Table 3). The exceeding of 1 indicates the possibility of an appearance of disturbances in target organs and systems (R 2.3.10.1920-04). Carcinogenic risk (CR) under human exposure with POPs from soil changes from $5.78 * 10^{-9}$ in rural area in the Hovsgol aimag to $2.32 * 10^{-8}$ in Ulaanbaatar. The $\mathrm{CR}$ values correspond to the first diapason that is taken by the population as negligible risk, not different from usual everyday risks. Such risks don't require additional measures for reducing risks and their levels are subject of periodical control (R 2.3.10.1920-04). PCBs bring the main contribution in total CR (8995 percents). The PCB contribution was followed by the contribution of $\mathrm{HCH}$ (2.7 8.3 percents), DDT and its metabolites (1.8 2.2 percents) and $\mathrm{HCB}(0.33-0.92$ percents $)$. The mean $\mathrm{CR}$ value under POPs inhalation exposure comes to $1.25^{*} 10^{-6}$. The value corresponds to the second diapason - the maximum permissible risk or upper level of permissible risk ( $\mathrm{R}$ 2.3.10.1920-04). The values can result from the overestimation of air levels (discussed above) and require an additional and seasonal investigation. The constant control is needed if the values will be confirmed.

Table 3. The hazard indexes (HI), carcinogenic risk (CR) and the contribution of individual groups of POPs in total CR under human exposure as a result of the inhalation of atmospheric air and accidental ingestion of soil by adult.

\begin{tabular}{|c|c|c|c|c|c|c|}
\hline \multirow{2}{*}{} & \multirow{2}{*}{ HI } & CR & \multicolumn{4}{|c|}{ the contribution in total CR, \% } \\
\cline { 4 - 7 } & & $\begin{array}{c}\text { total } \\
\text { PCBs }\end{array}$ & $\begin{array}{c}\text { total } \\
\text { DDTs }\end{array}$ & $\begin{array}{c}\text { total } \\
\text { HCHs }\end{array}$ & HCB \\
\hline $\begin{array}{c}\text { air, } \\
\text { mean }\end{array}$ & 0.029 & $\begin{array}{c}1.25^{*} \\
10^{-6}\end{array}$ & 92.5 & 1.97 & 4.9 & 0.60 \\
\hline $\begin{array}{c}\text { soil, } \\
\text { mean }\end{array}$ & 0.0003 & $\begin{array}{c}1.46^{*} \\
10^{-8}\end{array}$ & 91.2 & 2.58 & 5.9 & 0.32 \\
\hline
\end{tabular}

\section{Conclusions}

1. The concentrations of persistent organic pollutants in soil from Mongolia come to 3.97 - $13.2 \mathrm{ng} 28 \mathrm{PCBs} / \mathrm{g}$ dry weight, including $1.43-5.94 \mathrm{ng}$ indicator $\mathrm{PCBs} / \mathrm{g}$, $0.06-4.28 \mathrm{ng}$ total DDT/g, $0.02-0.81 \mathrm{ng}$ $\alpha+\gamma-\mathrm{HCHs} / \mathrm{g}$, and $0.0045-0.031 \mathrm{ng}$ $\mathrm{HCB} / \mathrm{g}$. The POPs distribution in the atmospheric air repeats the POPs distribution in soil on the area investigated.

2. The POPs levels in soil and air are lower than maximum permissible concentrations (MPC) and preliminary permissible concentrations (PPC) of PCBs and OCP accepted in Russia. POPs levels in Mongolian soil obtained in the investigation are comparable with those from background areas of the world. POPs levels in Mongolian air are in the frame of concentrations found in the world.

3. The PCB homological pattern in soil near electric power station in Ulaanbaatar corresponds to the homological pattern in technical mixture of PCB (Sovol or Arochlor 1254). The homological patterns in soil from other sites changed due to the redistribution of $\mathrm{PCB}$ congeners in the environment.

4. The ratio of $\alpha$ - and $\gamma$-isomers of $\mathrm{HCH}$ in soil from Mongolia indicate to predominant application of the technical mixture of $\mathrm{HCH}$ in the area of Ulaanbaatar and lindan in the Hivsgol aimag

5. The ratio DDT/DDE is higher in both soil and air from Mongolia that indicates fresh entrance of DDT in the environment of Mongolia due to the atmospheric transboundary transport from countries using DDT (China, India) or from local agricultural sources.

6. Hazard indexes as a result of the human exposure with POPs in soil and air are 2-4 orders lower than 1 that denotes the lack of disturbances in target organ and system. CR 
under the exposure with POPs from soil particles correspond to the first diapason that is taken by the population as negligible risk, not different from usual everyday risks. Such risks don't require additional measures for reducing risks and their levels are a subject of periodical control. The CR values under inhalation exposure with POPs correspond to the second diapason - the maximum permissible risk or upper level of permissible risk ( $\mathrm{R}$ 2.3.10.1920-04). The values can result from the overestimation of air levels (discussed above) and require additional and seasonal investigations. The constant control is needed if the values will be confirmed.The investigation was supported by RFFI № 10-05-93173-Mong_a and 10-05-00663-a

\section{References}

1. Laiguo Chen, Yong Ran, Baoshan Xing, Bixian Mai, Jianghua He, Xiuguo Wei, Jiamo $\mathrm{Fu}$ and Guoying Sheng Contents and sources of polycyclic aromatic hydrocarbons and organochlorine pesticides in vegetable soils of Guangzhou, China // Chemosphere. - 2005. - Vol. 60, Issue 7. - P. 879-890

2. Goreglyad A.V., Mamontov A.A., Tarasova E.N., Vetrov A.S., Mamontova E.A. The comparison of the composition of persistent organic pollutants (POPs) in zooplankton and sediment of Lake Hovsgol and Lake Baikal // In: Lake ecosystem: biological processes, anthropogenic transformation, water quality. - Minsk, Naroch: Publish Center of BGU, 2007. - P. 211-212. (in Russian).

3. Grimalt J.O., van Drooge B.L., Ribes A., Vilanova R.M., Fernandez P., Appleby P. Persistent organochlorine compounds in soils and sediments of European high altitude mountain lakes // Chemosphere. 2004. - Vol. 54. - P. 1549-1561.

4. Ivanov V. and Sandell E. Characterization of polychlorinated biphenyl isomers in Sovol and Trichlorodiphenyl formulations by high-resolution gas chromatography with electron capture detection and highresolution gas chromatography - mass spectrometry techniques // Environ. Sci. Technol. - 1992. - Vol. 26. - P. 2012-2017.
5. Jaward F.M., Farrar N.j., Harner T., Sweetman A.J., Jones K.C. Passive air sampling of PCBs, PBDEs, and organochlorine pesticides across Europe // Environ. Sci. Technol. - 2004. - 38. - 3441.

6. Jaward F.M., Zhang G., Jae Jak Nam, Sweetman A.j., Obbard J.P., Kobara Y., Jones K.C. Passive air sampling of polychlorinated biphenyls, organochlorine compounds, and polybrominated diphenyl ethers across Asia // Environ. Sci. Technol. - 2005. - 39. - 8638-8645.

7. Lkhasuren Jargalsaikhan, Battulga Perevdorj. National implementation plan for the Stockholm Convention. Mongolia. GEF/UNIDO, 2006. - 126 p. (http://www.chm.pops.int).

8. Mamontov A.A., Mamontova E.A., Tarasova E.N., Kuzmin M.I., McLachlan M.S. Persistent organic pollutants in soil and snow from the Lake Baikal Region // Organohalogen compounds. - 2004. - Vol. 66. - P. 1327-1332.

9. Mamontova E.A., Kuzmin M.I., Tarasova E.N., Goreglyad A.V., Tkachenko L., Khomutova M.Iu. PCBs and OCPs in some media from Lake Hovsgol and surrounding area, Mongolia // Organohalogen Compounds. - 2009a. Vol. 71. - P. 2969-2973.

10. Mamontova E.A., Kuzmin M.I., Tarasova E.N., Khomutova M.Yu. Distribution of PCBs and OCPs in air in the Irkutsk region, Russia // Organohalogen Compounds. - 2009b. Vol. 71. - P. 2869-2873.

11. Meijer S.N., Ockenden W.A., Sweetman A., Breivik K., Grimalt J.O., Jones K.C. Global distribution and budget of PCBs and HCBs in background surface soils: implication for sources and environmental processes // Environ. Sci. Technol. - 2003. - Vol. 37. - P. 667-672.

12. Mel'nikov N.N. Pesticides. Chemistry, technology and application. M.: Chemistry, 1987. - 712 p. (in Russian).

13. Pozo K., Harner T., Wania F., Muir D.C.G., Jones K., Barrie L.A. Toward a global network for persistent organic pollutants in air: results from the GAPS 
study // Environ. Sci. Technol. - 2006. 40. - 4867-4873

14. Pozo K., Harner T., Sum Chi Lee, Wania F., Muir D.C.G., Jones K.C. Seasonally resolved concentrations of persistent organic pollutants in the global atmosphere from the first year of GAPS study // Environ. Sci. Technol. - 2009. Vol. 43. - P. 796-803.

15. Shoeib M., Harner T. Characterization and Comparison of Three Passive Air Samplers for Persistent Organic Pollutants // Environ. Sci. Technol. - 2002. - Vol. 36. - P. 4142-4151.

16. Sunden A. The urgent international movements in with respect to persistent organic pollutants // Proceedings of sub regional meeting on revelation and assessment of persistent organic pollutants (POPs) emission. - M.: Center of international project, 1998. - P. 210-232. (in Russian).
17. Wania F., Mackay D. Tracking the distribution of persistent organic pollutants // Environ. Sci. Technol. - 1996. - Vol. 30. - C. 390A-396A.

18. Weiss P., Lorbeer G., Scharf S. Regional aspects and statistical characterization of the load with semivolatile organic compounds at remote Austrian forest sites // Chemosphere. 2000. - Vol. 40. - P. 1159-1171.

19. Zhang G., Chakraborty P., Li J., Sampathkumar P., Balasubramanian T., Kathiresan K., Takahashi S., Subramanian A., Tanabe S., Jones K.J. Passive atmospheric sampling of organochlorine pesticides, polychlorinated biphenyls, and polybrominated dyphenyl ethers in urban, rural, and wetland sited along the coastal length of India // Environ. Sci. Technol. 2008. - Vol. 42. - P. 8218-8223. 